\title{
Editorial
}

\section{Drug safety: can more be done?}

A few months ago, at a private meeting held in Newfoundland, a number of people who were deeply concerned about ensuring the safety of pharmaceuticals met to consider how far drug safety has advanced in the 35 years since the thalidomide disaster shocked the world into acute awareness that medicines could be tragically dangerous. The meeting was deliberately held in private because it represented an attempt to bring together people whose views were so mutually divergent that the discussion was likely to reflect all the extreme views which are held on the matter, ranging from complacency to alarm; behind closed doors there was no need to hide facts or to seek compromises. What was sought was an inventory of the situation, of whatever need for change there might be, and of the opportunities which may exist to do better.

Nothing was published from that meeting, nor will anything be published in the future. But the participants all returned home with a greater awareness of what remains to be done, and how they might strive, each in their own way, to achieve it. It is against the background of that experience in a closed circle that one is bound to view the impressive series of papers from an International Symposium on the same subject which was held in Germany early in 1996 and which is the subject of this issue.

It is no criticism of what has transpired at this and earlier public symposia to say that it reflects to an important extent the positive side of the thirty-five years of progress. The paper by Beckmann in particular presents an imposing portrait of the manner in which one major regulatory agency - that of Germany - today seeks to ensure that drugs are sufficiently safe; a vast amount of effort and expertise is expended to that end, both at the time when a drug is first assessed and later as new reports of possible risk are evaluated. That effort at the national level is in part dependent today on international collaboration and support. Richard Lee describes the European edifice developed to ensure drug safety within a Community of fifteen states which has increasing power to ensure that throughout its area the same high standards are maintained. At the global level, one has the World Health Organization's international collaborative system for recording and disseminating adverse reaction reports from more than forty countries; and that in turn is complemented by the work of CIOMS, described by Bankowski, which has taken on the essential task of ensuring that industry and government work in tandem to the same end. All these accounts are exhaustive, balanced, sober. So does any reason for concern remain?

The answer undoubtedly is that it does. One could advance three reasons for remaining at least very watchful and at most concerned.

Firstly, it is very striking that the progress which has been made, even at the global level, still reflects the state-of-the-art and of the business in developed, industrialized countries. It is splendid to see how the efforts made both at the government and the industrial level have advanced in that 
part of the world. Yet it is worrying to turn from there to the situation in a large number of developing countries which on the one hand do not have the means to protect their populations and on the other hand are exposed to sources of risk almost unknown in the industrialized West. Anyone who has examined the situation in a number of African countries will subscribe to the conclusion of the World Health Organization that something like a third of the drug products on sale there must be characterised as false, spurious or substandard; many are ineffective, a high proportion are dangerous. They appear to originate largely in Asian countries at a medium level of development where pharmaceutical exports are burgeoning yet industry is largely out of control. The problem lies here not with the supposedly wicked multinationals, who have largely been preached or cajoled into conformity, but with opportunists operating factories in the backstreets. It is bad enough to find them still selling phenacetin and aminopyrine on a large scale; it is far worse to find them selling unsterile penicillin, deteriorated tetracycline (which can be highly nephrotoxic) and obscure chemicals which have never been the subject of serious study at all. There are also other loopholes in the global system; one still, in September 1996, found in a Mongolian warehouse a large stock of a German drug, supplied in 1994 by a supposedly altruistic European donor, the shelf-life of which had expired in 1991. And in developing countries one still runs into herbal and traditional remedies, often of purely local significance, which appear to carry risks to the adult organism or the unborn child.

The second source of concern is that even within western industry one still in the nineties runs into serious instances where risk data have been concealed in the interests of commerce. Only those engaged in litigation - including litigation between drug companies - and having access to internal files produced on discovery by Court order, actually see these data, and their lips are likely to be sealed by oaths and agreements with attorneys. Two very serious epidemics of hepatotoxicity were allowed to persist in Western European countries longer than necessary because fact-finding was impeded and indeed sabotaged. Year by year one hopes that the people behind these scandals-in-the-shadows will learn; perhaps they do, but year by year one sees others falling into the same errors. Consciences are sometimes elastic; and behind closed doors optimism sometimes still prevails over honesty and good sense.

The third source of concern is much more difficult to define in concrete terms, for it relates to fear of the utterly unknown. However far and fast the procedures to ensure drug safety advance, there is always the basic risk that they will be concerned primarily with risks the nature of which is recognized. We are today wide awake to the possibility that drugs may adversely affect the foetus, damage the liver or derange the sense of balance, because all these things have happened in the past. But how soon shall we recognize a late association between marihuana and Alzheimer's disease? Or between invitro fertilization and adult intelligence? Or between genetically manipulated hormones and metabolic disease? These are theoretical examples but so thirty-six years ago was the notion that a drug could acutely injure the foetus; thirty-five years ago one still actually scoffed at people who proposed long-term monitoring of the effects of oral contraceptives.

To say this is not to be alarmist; the very purpose is to avoid the need for alarm. Everything that has been achieved to date to promote drug safety is commendable and most of it (except for some unrealistic toxicity studies) must continue; but all the time we need to look further. New drugs are needed and risks are bound to follow in their wake; the more novel these drugs and the more radical their mode of action, the more unpredictable their late effects may be. One cannot prepare for the entirely unforeseeable, but with effort one will learn to look further ahead than we can at present and recognize correlations between cause and unwanted effect more rapidly. As someone remarked 
at a recent meeting: "We are already bending over backwards to avoid risk...". But as someone else replied: "Yes, but you may be bending over backwards to shut the stable door after the horse has gone". Perhaps; in any field of endeavour, society tends to scurry to catch up with today's problems; but where medicines are concerned, preparing a safety net for the problems which may land on us tomorrow is likely to be at least as rewarding.

Graham Dukes Editor-in-Chief 